Article

\title{
Playing for a Sustainable Future: The Case of We Energy Game as an Educational Practice
}

\author{
Tania Ouariachi *(D, Wim J. L. Elving and Frank Pierie \\ Professorship Communication, Behaviour \& the Sustainable Society, Center of Expertise Energy, \\ Hanze University of Applied Sciences, Zernikeplein 7, 9747 AS Groningen, The Netherlands; \\ w.j.l.elving@pl.hanze.nl (W.J.L.E.); f.pierie@pl.hanze.nl (F.P.) \\ * Correspondence: t.ouariachi.peralta@pl.hanze.nl
}

Received: 19 September 2018; Accepted: 9 October 2018; Published: 11 October 2018

check for updates

\begin{abstract}
Energy transition is key to achieving a sustainable future. However, in this transition, an often neglected pillar is raising awareness and educating individuals on the benefits, complexities, and urgency of renewable energy supply and energy efficiency. This paper exemplifies an educational practice to create awareness on sustainable energy transition by playing a "serious" game, the We Energy Game. Concretely, this qualitative study aims to analyze communicational and educational aspects of the game by making use of a validated framework for serious games analysis, and to expose the opinion of players after maintaining group discussions. The analysis reveals a detailed insight of narrative elements, messages, and gameplay mechanisms, but also educative aspects to be considered by teachers if they are interested in putting the game into practice in their classes. The group discussion reveals that the game has been more successful in achieving cognitive (understanding/knowledge) and affective (emotion/interest and concern) engagement than in motivating attitudinal or behavioral engagement.
\end{abstract}

Keywords: sustainability; energy transition; serious games; educational technologies

\section{Introduction}

Energy transition is key to achieving a sustainable future. Having more clean and affordable energy is, however, one of the main challenges that the world faces today: How can we provide the energy needed to support a growing global population and greater economic prosperity, without damaging our environment beyond repair? Most of the world's energy is supplied through the combustion of fossil fuels, releasing greenhouse gasses into the atmosphere which are responsible for the rising global temperatures and changing climate.

Responding to the challenges imposed by climate change and energy security, the EU and its member countries have set ambitious goals: to create a transition of the energy system by improving energy efficiency and increasing the share of renewables in the energy mix, in ways that would be compatible with (a) increasing competitiveness and security of supply, and (b) reducing greenhouse gas emissions by 80-95\%, when compared to 1990 levels, by 2050 [1]. To reach these goals, a range of stakeholders needs to take many different actions, including investing in renewable energy technologies, increasing the energy efficiency of buildings and appliances, and changing energy use behavior into energy-saving habits and practices.

In this transition, an often neglected pillar is raising awareness and educating individuals on the benefits of energy efficiency and renewable energy supply. Without support from local governments, private sector, or citizens, it would be impossible to achieve an energy transition for a sustainable future. Awareness and education also include understanding the urgency of the matter and understanding the complexities of the process: on the one hand, there are many available solutions to reach an 
optimal balance taking into account the point of view from all parties involved; on the other hand, sustainability is not just a technical issue, but a social one as well: even though there is a great support for solar panels, the sun does not always shine, so other resources are needed; wind provides a lot of energy, but can also encounter protest by local residents; biomass could be a good solution, but its yields are lower and its environmental footprint is greater.

Several studies have suggested that many communication and education efforts might have failed to raise awareness, and not necessarily because of little information being available, but because of the way information is conveyed [2,3]. The change in the mode of interaction means that existing communicative paradigms need to be revised, and that there is a need to move towards new formats that facilitate a natural interaction between the person, the interface, and the environment [4]. In search of innovative approaches, games are gaining attention among scholars and practitioners, especially in the education sector, as a tool to raise awareness on sustainability and energy transition, a prerequisite for taking action at the individual and collective level: games can foster skills and abilities, contribute to content development, and permit learning experiences that are not possible in real life $[5,6]$. However, not much research has been carried out in this innovative field of study. In addition, despite the raising interest by educators to use games in class, they still acknowledge to lack information on the nature of these resources, as well as on how to implement them in formal education [7-9].

This paper exemplifies an educational practice to create awareness on sustainable energy transition by playing a "serious" game. Within this paper, the We Energy Game (developed at the Center of Expertise Energy in Hanze University of Applied Sciences in Groningen, The Netherlands, under the project "From A to Sustainability") is used as a case study. The game tries to create awareness on the challenges in the provision of affordable energy from renewable sources for an entire town or city, by aiming for the creation of an ideal sustainable energy mix. During the game, players negotiate, from their respective roles, which energy source they want to employ and on which location, with the goal to make a town or city energy neutral. The We Energy Game has been played by a variety of groups, such as energy cooperative members, business, municipality representatives, and students. The concrete objectives of this paper are to analyze communicational and educational aspects of the game by making use of a validated framework for serious games analysis [10], and to expose the opinion of players after maintaining group discussions to understand what is working well or not. In order to provide context to the game, some facts about the energy transition panorama in The Netherlands, and an overview of serious games and gamified platforms focusing on energy issues, are firstly introduced.

\section{Energy Transition in The Netherlands: An Urgent Matter on the Agenda}

In adherence with the 2015 Paris Agreement-an agreement within the United Nations Framework Convention on Climate Change (UNFCCC) dealing with greenhouse gas emissions mitigation, adaptation, and finance-the Ministry of Economic Affairs of the Netherlands published an Energy Report with different focus areas, targeting the period of 2023-2050. Amongst other things, the report focuses on the integrating energy into the public space, since the transition to renewable sources will lead to transformations in the appearance of housing developments, business parks, and rural landscapes [11].

One of the recent announcements by the Dutch government is that they intend to invest $€ 300$ million in measures aimed at reducing carbon emissions in the Netherlands. The funds will be used for a series of projects, such as transitioning homes from natural gas to $\mathrm{H}$-gas (starting in Groningen), reducing carbon emissions from glasshouse horticulture and livestock farming, and introducing hydrogen fuel-cell vehicles and filling stations in the transportation sector [12].

In saying this, what is the public perception around climate change and energy transition in the Netherlands? The Global Attitudes Survey indicates that $56 \%$ of Dutch participants consider climate change as a major threat, only second after the threat of terrorism [13]. Comparing the figure with the 
perceived threat of climate change among other European countries, Netherlands ranks ninth out of ten, indicating relatively lower awareness than the rest of the countries, with the exception of Poland.

A study conducted by Hagen et al. [14] offer similar results, and also further insight into prioritization of the issue in public policy. The authors recognize that perception of climate change risk varies across contexts and cultural lines and, therefore, effective solutions cannot be worldwide "one-size fits all". Their study, integrating survey data collected from a representative sample of households in four European countries (including The Netherlands), measuring the public perceptions of political saliency, risk, trust, and attitudes regarding climate change. The study affirmed the indecisiveness of the participants. They conclude "a large number of people stated that they are uncertain about the danger [climate change] poses today or for future generations, and do not know which source of information to trust, resulting in indecisiveness of whether to support mitigation or adaptation strategies" (p. 180). While the research indicated high levels of concern about climate change, and the majority evaluated the level of risk of climate change consequences as "high" or "very high", the same participants marked climate change policy-making low in priority, among other societal problems. This suggests that the public attributes more importance to other immediate, tangible, and urgent needs, and that climate change remains an issue removed in time and space.

Public perception around the issue, therefore, is not fully in line with the urgency of the matter, and this is one of the areas where "serious" games-referred to as those games designed with a purpose that goes beyond pure entertainment-can play a pivotal role as communication and education tools.

\section{Energy-Related Gaming Strategies}

The widespread use of the internet, the need to create more engaging learning experiences, and the popularity of videogames in popular culture, has led to the emergence of the so-called serious games movement. They are intended to convey ideas and values, facilitate learning, and practice skills [15].

Education is one of the sectors that embraced serious games early on, as teachers recognized the potential of serious games: they are motivating, provide immediate feedback, can adapt themselves to the level of the learner, provide repetition to the point of automaticity, encourage distributed learning, can teach for transfer, and use other excellent teaching techniques [5].

In fact, today, serious games are one of the growing areas in educational media; its market is expected to grow from 3.2 billion U.S. dollars in 2017, to 8.1 billion in 2022 [16]. Serious games on sustainability and energy issues have grown and diversified exponentially over the last years but, especially, these types of games have experienced most progress in an online format. Different web platforms have appeared in recent years that serve as a directory of these types of games, such as Games4Sustainability or Gamepedia, targeting academics, trainers, NGOs, teachers, students, and anyone interested in this topic. Examples of serious games on energy issues include (Table 1):

Table 1. Examples of energy serious games.

\begin{tabular}{|c|c|c|}
\hline Game & Producer & Description \\
\hline WindMill Game & Persuasive Games & $\begin{array}{l}\text { Strategy game about building wind farms to create clean } \\
\text { energy profitably. Players fulfill a specified energy offset } \\
\text { goal as quickly as possible by building turbines smartly, } \\
\text { and research locations carefully for the best wind } \\
\text { conditions, avoiding upsetting the local citizens by } \\
\text { building turbines in undesirable places. }\end{array}$ \\
\hline Energy City & JASON Digital Lab & $\begin{array}{l}\text { In Energy City, players will work through a selection of } 6 \\
\text { cities, each has its own energy detail variations and } \\
\text { challenges, as they play a 10-year normal play, or a } \\
20 \text {-year expert play. Players must watch out for, and } \\
\text { observe, the important } 3 \text { meters displayed on the top of } \\
\text { their screen, providing details about the city's local air } \\
\text { quality, environmental impact, and budget. }\end{array}$ \\
\hline
\end{tabular}


Table 1. Cont.

\begin{tabular}{|c|c|c|}
\hline Game & Producer & Description \\
\hline Enercities & Paladin Studios & $\begin{array}{l}\text { In this game, the player is faced with the challenge of } \\
\text { developing an eco-friendly city dealing with issues such } \\
\text { as pollution, energy shortages, and renewable energy. } \\
\text { Players place buildings on a grid to grow their city. They } \\
\text { need to balance energy sources, cash flow, and the city's } \\
\text { economy, wellbeing, and environment. }\end{array}$ \\
\hline Electrocity & Genesis Energy & $\begin{array}{l}\text { Genesis has a goal of increasing public awareness by } \\
\text { sparking interest and laying the foundation for future } \\
\text { learning about key dilemmas related to energy } \\
\text { generation, cost of production, and environmental } \\
\text { impacts. The player becomes the mayor of a town, } \\
\text { starting by naming the town and giving population of } \\
10,000 \text { and a budget of } \$ 1000 \text {. From there, players have } \\
150 \text { turns of the game to make their town sustainable. }\end{array}$ \\
\hline
\end{tabular}

The application of game mechanics to non-game contexts to engage people has received the name of "gamification", a phenomenon that has also received substantially more attention in the last years [17]. In their State of Green Business report, the GreenBiz Group listed gamification as one of the top sustainable business trends, noting that game mechanics are increasingly used by companies to provide "rewards for making good, green choices" [18].

An example is The GenGame (GenGame, Open Energi, and Northern Powergrid), a gamified mobile tool created in England whose purpose is to make sure that people, through the fun experience, are changing their behaviors in terms of their energy use at homes [19]. As part of the project, there is a special tool connected to their main energy wire, through which all the energy used in home is transiting and reading how much energy is in use during a certain period of time. Over two years, the distribution network operator (DNO) convinced 2000 households to play the game: they received a signal ("It's GenGame Time!') to turn off household equipment; the more they cut consumption, the more points they won, and the greater the points won, the better their chances of getting the monthly prize draw, $£ 350$ in total, with a $£ 100$ top prize [20]. The developers of the game claim that if the game was played by the number of people living in England who were involved in the Pokémon Go, when it was at its peak, the extra energy saved with the help of the application would be enough to power 1 million households.

Another best practice took place in 2011 with Kukui Cup, an energy-saving competition for undergraduate students living in dormitories at the University of Hawaii at Manoa. Two open-source software infrastructures were created for the game: Watt Depot, to collect, store, analyze, and visualize electricity data; and Makahiki, a digital platform for the competition that could be personalized for other organizations' energy challenges. In the energy-saving competition, teams of students competed to reduce their kWh of electricity use; they could earn points by completing as many actions as possible from a list presented on the Makahiki website. The website recorded students' actions and gave them instant feedback in the form of points. The team with the lowest absolute electrical consumption in each round won. The points-based competition was designed to influence student behavior and to improve energy and environmental literacy technologies [21].

The use of serious games, gamification, and gameful design, in general, has proven to have potential as a way of inspiring awareness, acquiring understanding, and obtaining high participation rates in a broad audience who might, otherwise, not be motivated to care about climate change or carbon reduction, energy efficiency, and sustainability. 


\section{Methodology}

As stated in the introduction of this paper, the objective of this qualitative study is to exemplify an educational practice to achieve sustainability by making use of games. Concretely, the objectives are analyzing communicational and educational aspects of the game, and exposing the opinion of players after playing the game.

For the first objective, we make use of the validated checklist to analyze serious games related to climate change issues, such as energy, developed by Ouariachi et al. [10]. To come up with indicators that experts agree on for evaluating communicative and educative elements of these types of games, the authors use the Delphi method with a panel of 13 professionals from Spain, the United States, and the Netherlands, and with three consulting rounds: (1) sharing with experts a first draft of a checklist, containing dimensions (categories) and criteria (indicators) that integrate narratology, ludology and didactic perspectives, identified by the researchers through a literature review; (2) sharing with experts a questionnaire in which they evaluate (in high, medium, or low) the relevance and usefulness of 49 initial criteria in order to identify agreed and disagreed perspectives and achieve a first consensus. The criteria that got a consensus of $90 \%$ (high + medium) were chosen; (3) requesting a final opinion of the criteria that did not pass the second consulting round-14 out of 49-in order to know if they should stay outside the final selection of criteria. A third round was sufficient to achieve agreement and stability of results.

As a result of the queries, five dimensions of analysis were agreed upon: identification (features that help identify and locate the game); narrative (analysis of the narrative and fictional context elements); contents (analysis of the information and messages transmitted about climate change); gameplay (analysis of the game design and formal structures); and didactics (analysis of educational features). The criteria for each of the dimensions are exposed in the section of findings.

In the present study, five independent researchers from different countries participated in the coding and analysis of games. They played the game on separate computers, sharing a protocol with guidelines and definitions to fill in the checklist; they marked their responses and observations in different files, which later where combined into a single file after discussions. In this type of study, reliability is achieved by getting consistency of interpretation in coding from at least two researchers [22]. The inter-coder reliability shows to what extent different coders agree on the coding of the same material.

To achieve the second objective, we carried out a group discussion with 15 Dutch and international students, aged from 21 to 33, studying at Hanze University of Applied Sciences. The game session took place during a single class period in which the researchers introduced the game to students with a PowerPoint presentation ( $5 \mathrm{~min}$ ), and then let the students play in groups of five (40 $\mathrm{min})$. They all were asked to choose a role in the game and play two different levels. After finalizing the game, they participated in a group discussion $(15 \mathrm{~min})$ guided by the researchers. The discussion was aimed to be a collective exchange of ideas to share their opinions about the game. They were asked if the game was fun or boring and, if, after playing the game, they felt more aware and informed about energy transition, they felt they learnt something new, they were interested in learning more about the topic, and they were willing to change their own energy saving behaviors.

\section{Results}

\subsection{Game Analysis}

By making use of the validated dimensions and indicators vetted by the Delphi method, we begin a qualitative analysis to explore the communicative and educative elements of We Energy Game, while illustrating the use and usefulness of the indicators. The main observations are as follows:

Our analysis on the identification dimension (Table 2) shows that the creator of the game is an academic institution. This is important in order to ensure the validity and scientific accuracy of data. In fact, the developers of the game have integrated real data based on research focused on measuring 
and optimizing the sustainability of farm scale biogas production [23]. Scholars are calling for more involvement from academic institutions in the development of serious games, in a context where NGOs and private sector prevail [24].

When looking at the communicative purpose, researchers have chosen "developing familiarity with the topic" (Table 2). Considering that citizens and stakeholders are still not fully aware or engaged with the energy transition, this is a first step towards achieving a sustainable future. As mentioned earlier, public perception around the issue is not fully in line with the urgency of the matter. Developing familiarity with the energy transition involves, not only advantages and disadvantages of renewable energy sources, but also practical insights into energy possibilities, and the process of negotiation and collaboration required to achieve a sustainable energy solution.

Table 2. Findings on the identification dimension.

\begin{tabular}{lcccc}
\hline Name of the Game & URL & Creator & $\begin{array}{c}\text { Communicative } \\
\text { Purpose }\end{array}$ & Brief Description \\
\hline We Energy Game & He-energy.eu & $\begin{array}{c}\text { Hanze University } \\
\text { of Applied } \\
\text { Sciences/Center of } \\
\text { Expertise Energy }\end{array}$ & $\begin{array}{c}\text { Develop familiarity } \\
\text { with the topic }\end{array}$ & $\begin{array}{c}\text { The game play involves } \\
\text { collaboratively creating a } \\
\text { blueprint of a town with a } \\
\text { sustainable energy balance, } \\
\text { ensuring sufficient production, } \\
\text { the satisfaction of people, the } \\
\text { planet, financial viability, and a } \\
\text { balance in energy supply. }\end{array}$ \\
\hline
\end{tabular}

Despite that the narrative weight is low and there is no clear storyline as in books or movies, the game still offers different roles for players who immerse in a mission, creating a proper energy mix that satisfies production, people, planet, profit, and balance (Table 3). The different players aim at achieving their goals for their respective sectors, however, through playing the game, they will realize that without collaborating with the others, they will not be able to achieve their ultimate goal: a sustainable energy mix for their town. In the process, players also realize that there are many available solutions to reach an optimal balance, Considering the point of view from all roles involved in the game, and that sustainability is not just a technical issue, but a social one as well. For example, even though there is great support for solar panels, the sun does not always shine, so other resources are needed; wind provides a lot of energy, but can also encounter protest by local residents; biomass could be a good solution, but its yields are less and its environmental footprint is greater.

Table 3. Findings on the narrative dimension.

\begin{tabular}{|c|c|}
\hline & We Energy Game \\
\hline Relevance of narrative & Low \\
\hline Global storyline & $\begin{array}{l}\text { Challenges faced during the transition towards a sustainable community } \\
\text { from the perspective of different roles to create more collaboration and } \\
\text { discussion on the topic }\end{array}$ \\
\hline Character depiction and role & $\begin{array}{l}\text { - } \quad \text { Production: project leader who needs to produce energy } \\
\text { - } \quad \text { People: the citizens of the area where the game is played } \\
\text { - } \quad \text { Planet: how green/clean is the energy production } \\
\text { - } \quad \text { Brofit: how much profit is made by the different projects } \\
\text { network operator to work with is the energy source for the }\end{array}$ \\
\hline Representation of the environment & $\begin{array}{l}\text { Maps of municipalities in The Netherlands with icons representing energy } \\
\text { sources, houses, roads, green areas etc. The cities represented are Diever, } \\
\text { Meppel, Assen, and Emmen. }\end{array}$ \\
\hline Dimension/space/scale & Real/local \\
\hline Dimension/time & Present/future \\
\hline
\end{tabular}


The image above (Figure 1) is an example of locations portrayed in the game using real data and an open street map. In the Netherlands, population ranges from 500-5000 inhabitants in a village to $10,000-50,000$ inhabitants in a populated area, like a city. The purpose is that players realize that the larger the locations are, the more challenging to achieve common goals and keep all characters satisfied.

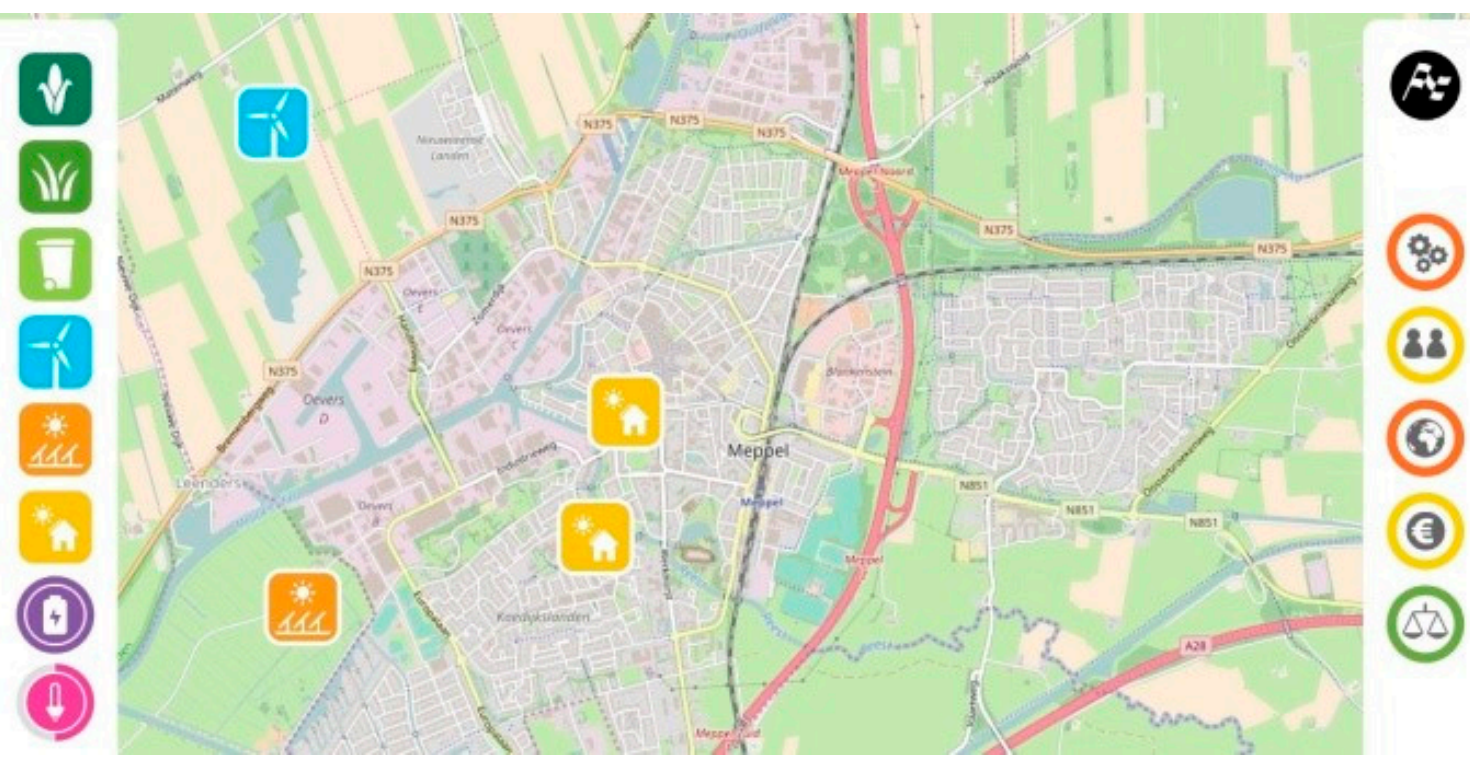

Figure 1. Map of Meppel. Courtesy of Hanzehogeschool@.

Not only do games allow players to immerse themselves in a virtual world with thematic frameworks different to those offered by the traditional media, such as consumption, citizen participation, or urban planning, but they are also able to convey the causes and consequences of their actions. Another interesting aspect is that messages sent through the game emphasize solutions, rather than problems, under an informative and pro-action tone (Table 4).

Table 4. Findings on the contents dimension.

\begin{tabular}{cc}
\hline Explicit use of scientific concepts & $\begin{array}{c}\text { We Energy Game } \\
\text { Explicit use of information sources } \\
\text { roofs, wind turbines, biogas }\end{array}$ \\
\hline Convergence with social networks & No \\
\hline Message framework & No \\
\hline & $\begin{array}{c}\text { Topics: energy, consumption, citizen participation, urban planning } \\
\text { Causes: high greenhouse gases emissions } \\
\text { Message tone: informative, pro-action }\end{array}$ \\
\hline
\end{tabular}

As with the majority of serious games related with sustainable issues [24,25], the We Energy Game also focuses on climate change mitigation, understood by United Nations as efforts to reduce or prevent emission of greenhouse gases. Mitigation can mean using new technologies and renewable energies, making older equipment more energy efficient, or changing management practices or consumer behavior. It can be as complex as a planning a new city, or as a simple as improvements to a cook stove design.

Energy sources that are addressed in the game include large solar parks, solar panels on roofs, large wind turbines, and biogas production using co-digestion of either energy maize, municipal waste, or agricultural waste. Additionally, there is the option for energy storage and increasing energy 
efficiency (e.g., switching to LED lighting can save households about 70\% of the energy, and insolation of houses reduces energy use, and on that way greenhouse gasses emissions).

Our findings reveal that challenge is one of the main game dynamics, translated into decision-making and time pressure as the main strategies (Table 5). Players must take various parameters into account in real time, prioritizing considerations and planning resources in a strategic way, by critically analyzing and evaluating information received. In fact, decision-making under time pressure is considered a key skill to coping with climate change effects. Another one is collaboration. We Energy Game is a good example of how serious games can employ cooperation mechanics, which is an element missing in the majority of these types of serious games [3,25].

Table 5. Findings on the gameplay dimension.

\begin{tabular}{cr}
\hline No. players/use & We Energy Game \\
\hline Length of play & $1-5$ players/collective use \\
\hline Mission & $\begin{array}{r}\text { To make a town or city energy neutral: players negotiate from their } \\
\text { respective roles which energy source they want to employ and on which } \\
\text { location. Once agreement is reached, they place the icon that represents that } \\
\text { energy source on the map and they check the consequences for each of the } \\
\text { roles (production, people, planet, profit, and balance) }\end{array}$ \\
\hline Degree of interactivity & $\begin{array}{r}\text { Medium } \\
\text { Dynamics and mechanics }\end{array}$ \\
\hline Player type & $\begin{array}{c}\text { Dynamics: challenge, collaboration, altruism } \\
\text { Mechanics: decision-making, time pressure, cooperation }\end{array}$ \\
\hline Feedback system & Positive (when icons turn green) and negative (when icons turn red) \\
\hline Reward system & No
\end{tabular}

The scores are based on realistic effects of each variable and refer to the amount of energy, emissions, and impact. The game uses four levels of difficulty by making use of four different maps in The Netherlands, allowing players to experience the challenges of making different towns with different populations sizes and urban structures energy neutral: Diever (goal: 25 points), Meppel (50 points), Assen (75 points), Emmen (100 points).

The game finishes when all roles reach the total score for the selected town, maintaining a positive balance. This is achieved by using different energy sources which each provide a certain amount of points for each role. By placing these sources on a map, players achieve these points. Most energy sources have some positive and negative scores for the roles, so the solution should be a mix of all the sources available.

The image above (Figure 2) shows the fingerprint of two of the renewable energy sources in the We Energy Game. Every role receives an amount of points per resource, which van differ between resources. For instance, for the role "balance" the score for "Biogas Maize CHP" is positive, whereas the "Big wind turbine" scores negative. Within this context, a mix of resources is required to reach a common goal.

Finally, the analysis shows the potential of these resources to be implemented in class (Table 6). On the one hand, they cover a variety of key competences and abilities. They can be integrated into XXI century skills-learning and innovation skills (critical thinking and problem solving), digital literacy skills, and career and life skills (adaptability, social interaction, accountability). On the other hand, these games are characterized to be interdisciplinary, which means that they can be used simultaneously for different disciplines, such as social studies or environmental studies, and to allow group work in class. As a limitation, the game does not provide specific guidelines on how to use the game, in class, by educators. 


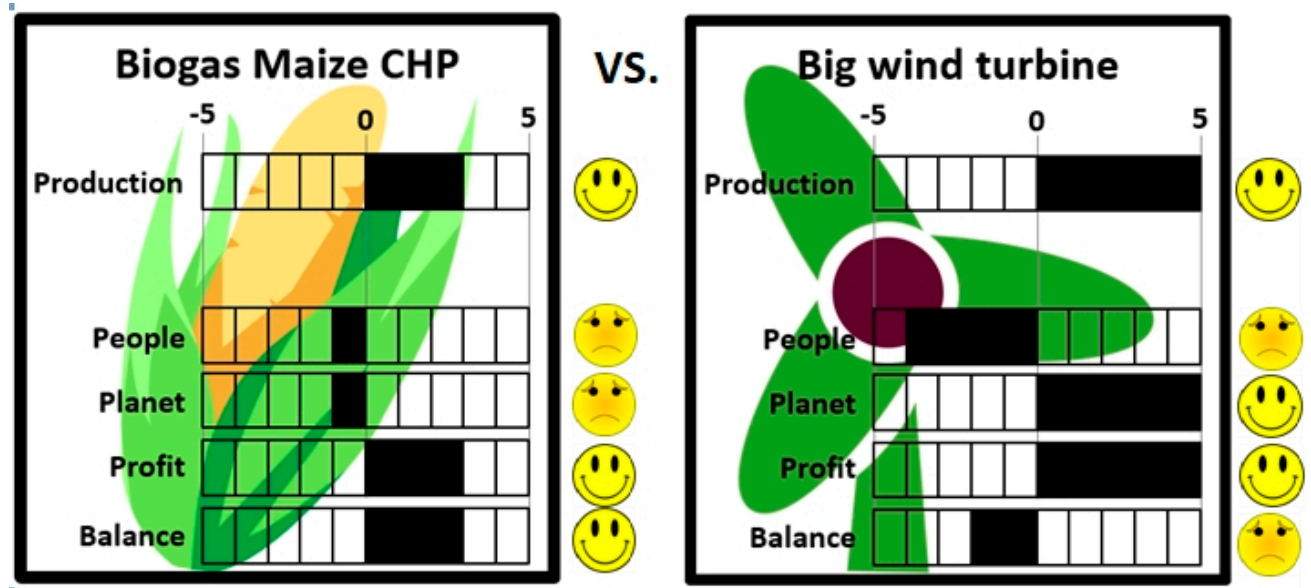

Figure 2. Results. Courtesy of Hanzehogeschool@.

Table 6. Findings on the didactics dimension.

\begin{tabular}{|c|c|}
\hline & We Energy Game \\
\hline Competences & $\begin{array}{l}\text { Social and citizen competence, knowledge and interaction with the } \\
\text { physical world, autonomy and personal initiative }\end{array}$ \\
\hline Abilities & Remember, understand, apply, analyze \\
\hline Problem resolution conditions & Reproductive reasoning and productive reasoning \\
\hline Need for previous knowledge & Limited \\
\hline Level of difficulty & Low \\
\hline Possibility of group work & Yes \\
\hline Interdisciplinary & Yes (social studies, science, mathematics) \\
\hline Existence of didactic guidelines & No \\
\hline
\end{tabular}

\subsection{The Opinion from Players}

Players found the game a fun and educational experience. They enjoyed being encouraged to take decisions and work collaboratively to achieve the game goal. They thought it was an interesting way to gain insights on the complexities to plan a sustainable energy transition in a given town. Two students also found game dynamics and rules too easy, so after a while, they lost some motivation in the game. That same criticism is presented by game scholars, who believe that educational games usually have difficulties achieving the high levels of engagement associated with commercial games.

Except for one student, all students confirmed feeling more aware and informed about energy transition after playing the game. The game provided the students a first contact and overview to this topic, including different clean energies alternatives, use of space, energy efficiency, and energy balance. The image below (Figure 3) shows an example of how the game teaches in an interactive way about the use of space, concretely, and how solar panels PV fields can be perfectly placed on farmlands but not in an area with households.

Overall, they became more aware of the challenges in the provision of affordable energy from renewable sources for an entire town or city, creating an ideal sustainable energy mix with positive outcomes for society and the planet. They acknowledged having realized the importance of communication in group decision-making processes. Other learning aspects were also revealed during discussions:

\footnotetext{
"There seems to be a general dislike towards wind turbines among the Dutch population"

"Solar panels can't provide enough sun for everyone"

"The difficulty of satisfying people while staying green and having a good profit"

"All players/roles need to be taken into consideration for a sustainable energy transition, and that it is a lot harder than it seems to keep every party happy"
} 
Practically all students prefer the game as a pedagogical method to learn about sustainability and energy transition compared to a traditional class (41.7\% a lot; $50 \%$ quite a lot; $8.3 \%$ not so much; $0 \%$ not at all). After playing the game they were able to provide solutions for a sustainable energy transition in the situations they were confronted with during the game, showing a high degree of reflection and critical thinking. In addition, the majority would like to learn more about the topic after playing the game ( $25 \%$ a lot; $58.3 \%$ quite a lot; $16.7 \%$ not so much; $0 \%$ not at all). However, students acknowledge that the game does not have an effect on their willingness to change their own attitudes and behaviors in energy saving and energy efficiency because (a) the game does not provide specific instructions for individuals or (b) they are already engaged in sustainable actions.

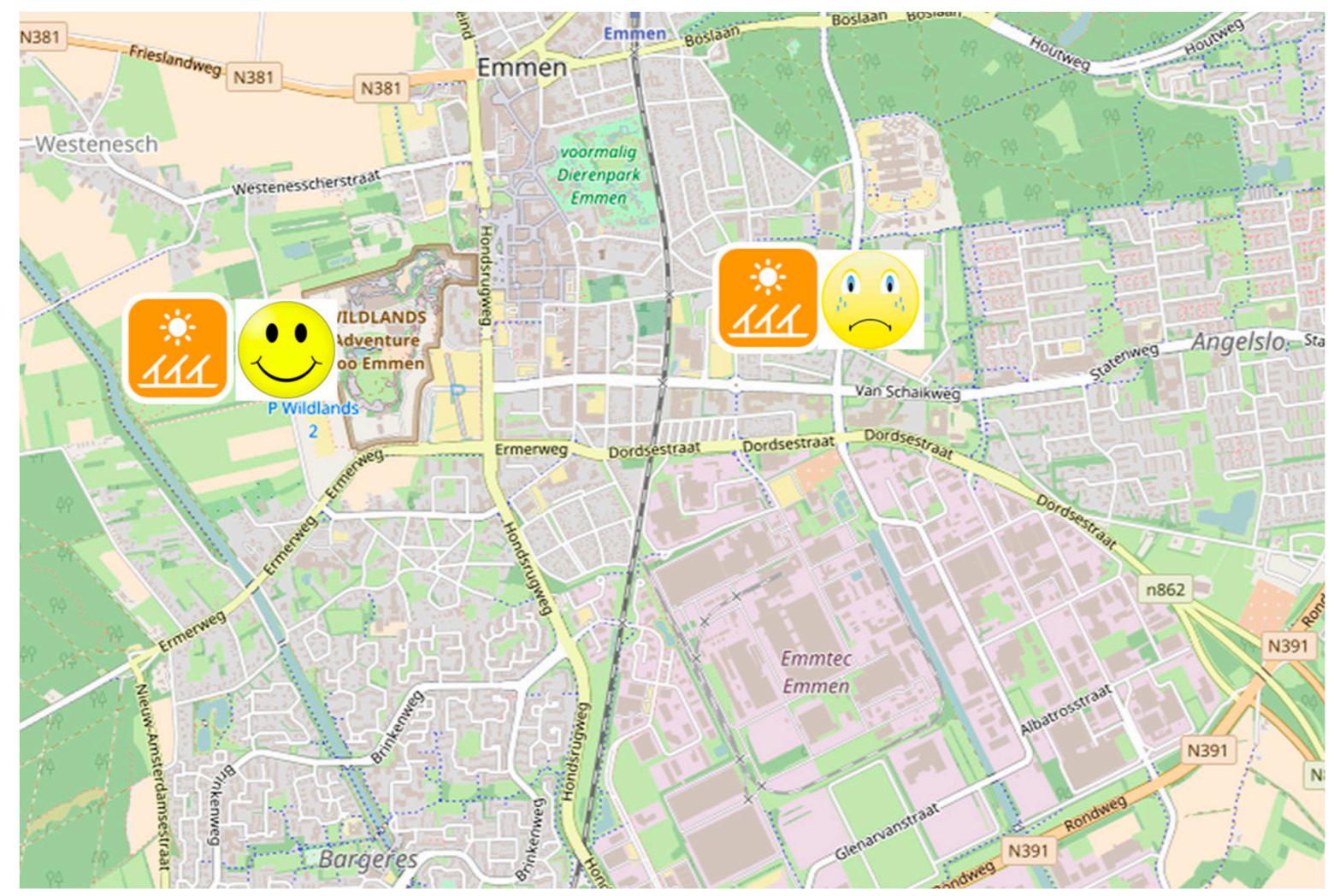

Figure 3. Placing energy sources on the map. Courtesy of Hanzehogeschool@.

\section{Discussion and Conclusions}

Using We Energy Game as a case study, this paper offers insights into an innovative field of study, not just by highlighting the opportunities of using digital technologies in order to create awareness on a sustainable energy transition, but also by offering a detailed analysis of communicative and educative features of a single game (example of applied research), and by exposing the opinion of players after playing the game. In addition, the paper shows a tool with validated criteria to create or analyze these types of serious games. The tool can be applied for decision-making by educators before selecting an appropriate game to be implemented in class; it helps to reveal narrative elements, messages, and gameplay mechanisms, but also pedagogical aspects to be considered. Practitioners and scholars are encouraged to use the set of validated criteria exposed in this paper.

The group discussion reveals that the game has been successful in achieving cognitive (understanding/knowledge) and affective (emotion/interest and concern) engagement, making players get practical insight into energy possibilities, understand the advantages and disadvantages of renewable energy sources, be concerned about the complexities and the urgency for a sustainable energy transition, and experience the negotiation and collaboration required to achieve this goal. However, the game has been less successful in motivating attitudinal or behavioral engagement. The discussion 
also reveals how serious games have still a long way to go to achieve the high levels of engagement of commercial games. Despite that, students still preferred to have this type of interactive practice, rather than a traditional class characterized by a unidirectional transmission of information.

It is out of the scope of this study to test the effectiveness of the selected game in pursuing its goals, but we can mention that there is still insufficient empirical evidence to prove effectiveness of serious games. Van Pelt et al. [26] have found positive changes in awareness and understanding, although no statistically significant differences between experimental and control group. Soekarjo and van Oostendorp [27] have found, in their review, increased knowledge of players in five of the sixty games reviewed, change in attitude in five games, and change in behavior in three games, after playing them. More research in this field is highly encouraged. Whether we have sufficient empirical evidence or not, as researchers and educators, it would be a mistake to not considering current educational and digital tools, such as videogames, to achieve a sustainable future.

Regarding future applications, game developers of We Energy Game are planning to move one step further and develop gamified platforms to move from awareness to action: a We Energy Saver to help individuals save energy, and a We Energy Tool that helps individuals plan the transition to renewable energy in a local setting.

Author Contributions: Conceptualization, T.O.; methodology, T.O.; validation, T.O., F.P. and W.J.L.E.; formal analysis, T.O.; investigation, T.O.; data curation, F.P. and W.J.L.E.; writing—original draft preparation, T.O.; writing-F.P. and W.J.L.E.; supervision, W.J.L.E.

Funding: This research received no external funding.

Acknowledgments: We would like to thank Roel van Veen, Mathieu Przybyla, Raquel Ortiz, Svetlana Bikulich, Chesley Ryder, Sasha Jurchak, and Shubhra Dixit for their valuable contribution.

Conflicts of Interest: The authors declare no conflict of interest.

\section{References}

1. European Union Commission. 2050 Energy Roadmap. Available online: https://ec.europa.eu/energy/en/ topics/energy-strategy-and-energy-union/2050-energy-strategy (accessed on 2 May 2018).

2. Moser, S. Communicating Climate Change: History, Challenges, Process and Future Directions. WIREs Clim. Chang. 2010, 1, 31-53. [CrossRef]

3. Reckien, D.; Eisenack, K. Climate Change Gaming on Board and Screen: A review. Simul. Gaming 2013, 44, 253-271. [CrossRef]

4. Garrido-Miranda, J.M. Videojuegos de estrategia: Algunos principios para la enseñanza. Rev. Electrón. Investig. Educ. 2013, 15, 1-12.

5. Gee, J.P. Lo Que nos Enseñan los Videojuegos Sobre el Aprendizaje y el Alfabetismo; Aljibe: Archidona, Spain, 2004; ISBN 84-9700-168-0.

6. Prensky, M. Digital natives, digital immigrants. Horizon 2001, 9, 1-6. [CrossRef]

7. $\mathrm{Wu}, \mathrm{J}$; Lee, J. Climate change games as tools for educational and engagement. Nat. Clim. Chang. 2015, 5, 413-418. [CrossRef]

8. Flora, J.A.; Saphir, M.; Lappé, M.; Roser-Renouf, C.; Maibach, E.W.; Leiserowitz, A.A. Evaluation of a national high school entertainment education program: The Alliance for Climate Education. Clim. Chang. 2004, 127, 419-434. [CrossRef]

9. Knock, E.; De Vries, P.W. EnerCities, a Serious Game to Stimulate Sustainability and Energy Conservation: Preliminary Results; eLearning Papers; Elsevier: Amsterdam, The Netherlands, 2011.

10. Ouariachi, T.; Gutiérrez-Pérez, J.; Olvera-Lobo, M.D. Criterios de evaluación de juegos online sobre cambio climático: Aplicación del método Delphi para su identificación. Rev. Mex. Investig. Educ. 2017, 22, 445-474.

11. Ministry of Economic Affairs. Energy Report Transition to Sustainable Energy; Ministry of Economic Affairs: The Hague, The Netherlands, 2016.

12. Government of The Netherlands. Government to Invest $€ 300$ million in Climate Measures. Available online: https:/ / www.government.nl/latest/news/2018/03/09/government-to-invest-\%E2\%82\%AC300million-in-climate-measures (accessed on 2 May 2018). 
13. Pew Research Center. Global Attitude Survey 2017. Available online: http:/ / www.pewglobal.org/ (accessed on 2 June 2018).

14. Hagen, B.; Middel, A.; Pijawka, D. European Climate Change Perceptions: Public support for mitigation and adaptation policies. Environ. Policy Gov. 2016, 26, 170-183. [CrossRef]

15. Frasca, G. Play the Message: Play, Game and Video Game Rhetoric. Ph.D. Thesis, IT University of Copenhagen, Copenhagen, Denmark, 2007.

16. Statista. Game-Based Learning Market Revenue Worldwide in 2017 and 2022 (in Billion U.S. Dollars). Available online: https://www.statista.com/statistics/733616/game-based-learning-industry-revenueworld/ (accessed on 2 June 2018).

17. Marczewski, A. Gamification: A Simple Introduction; Amazon.com: Seattle, WA, USA, 2012.

18. Makower, J. State of Green Business. Green Biz Report. Available online: https://www.greenbiz.com/ article/state-green-business-2017 (accessed on 2 July 2018).

19. Baldwin, A. Could Gamification Hold the Key to Driving Demand Response? Edie.net. Available online: https: / / www.edie.net/news/8/Could-gamification-hold-the-key-to-driving-demand-response- / (accessed on 2 July 2018).

20. Coyne, B. Northern Powergrid Applies Gamification to Engage Domestic DSR, EVs Next. Available online: https: / theenergyst.com/gengame-time-northern-powergrid-applies-gamification-domestic-dsrevs-next/ (accessed on 2 May 2018).

21. Brewer, R. Fostering Sustained Energy Behavior Change and Increasing Energy Literacy in a Student Housing Energy Challenge. Ph.D. Thesis, University of Hawaii, Honolulu, HI, USA, 2013.

22. Neuendorf, K. The Content Analysis Guidebook; Sage Publ.: London, UK, 2002.

23. Pierie, F. How to Measure and Optimize the Sustainability of Complex (Renewable) Energy Production Pathways: Applied to Farm Scale Biogas Production Pathways. Ph.D. Thesis, University of Groningen, Groningen, The Netherlands, 2018.

24. Katsaliaki, K.; Mustafee, N. Edutainment for Sustainable Development: A survey of Games in the Field. Simul. Gaming 2014, 46, 647-672. [CrossRef]

25. Ouariachi, T.; Olvera-Lobo, M.D.; Gutiérrez-Pérez, J. Analyzing climate change communication through online games: Development and application of validated criteria. Sci. Commun. 2017, 38, 10-44. [CrossRef]

26. Van Pelt, S.C. Communicating climate (change) uncertainties: Simulation games as boundary objects. Environ. Sci. Policy 2015, 45, 41-52. [CrossRef]

27. Soekarjo, M.; van Oostendorp, H. Measuring Effectiveness of Persuasive Games Using an Informative Control Condition. Int. J. Serious Games 2015, 2, 37-56. [CrossRef] 